\title{
Phenology of ectomycorrizal fungi in subtropical evergreen Castanopsis forest
}

\section{Morten Christensen}

University of Copenhagen, Faculty of Life Science, Center for Forest, Landscape and Planning, Rolighedsvej 23, 1958

Frederiksberg C, Denmark

\begin{abstract}
The mycota of Himalaya is poorly described and information on the ecology of ecto-mycorrhizal species in the region is very limited. Three years (2004-2006) of intensive studies of the fruitbodies in Schima-Castanopsis forest in Central Nepal have documented a high diversity of ecto-mycorrhizal fungi. Systematic information collected from five forests in the surrounding of Pokhara are analyzed to describe the phenological patterns. The species diversity of fruitbodies is highest just after the first pre-monsoon rainfall in late May to early July and by the late monsoon rain of September and early October. Similar bimodular patterns are described from areas with warm humid climate in Japan. In cold Temperate and Boreal areas in Europe and North America as well as in the mountainous areas of Nepal only one peak of the ecto-mycorrhizal fungi is found. In these areas the temperature seems to be the main agent in determining the time of fructification of the ecto-mycorrhizal fungi. In contrast studies from Subtropical Mediterranean climate in Southern Europe with winter rain found fructification in the cold season, indicating that moisture is more crucial for the fruitbody creation than temperature in subtropical areas.
\end{abstract}

Key-words: Central Nepal, ecto-mycorrhiza, Himalaya, Schima-Castanopsis forest.

\section{Introduction}

The Himalayan region is known to be a global hotspot for the diversity of higher plants, but the mycota of the region is still poorly described. Basic information on composition and ecology of ecto-mycorrhizal species in the region is limited to a few studies (Adhikari and Parajuli 1996; Adhikari 2000). The present paper presents the results of three years of intensive studies of the fruitbodies of ecto-mycorrhizal fungi in subtropical SchimaCastanopsis forest in Central Nepal.

The fruiting of ecto-mycorrhizal fungi is highly seasonal and depends mainly on moisture and temperature. In temperate and boreal ecosystems, the temperature is often the main agent and low winter temperatures often limit the growth of fungi. In subtropical forest, the temperatures are rarely low enough to limit the growth of fungi. In Mediterranean subtropical areas of southern Europe, the main rainfall is in winter time and this is also the main season for the ecto-mycorrhizal fungi, despite the lower temperature (Richard et al. 2004). Pokhara valley in Central Nepal has an extreme seasonal variation in rainfall with wet and hot monsoon summers and very dry but mild winters. Normally, the time before the monsoon start in May and June is characterized by frequent and heavy thunderstorms in combination with high temperatures. The forest type dominated by Castanopsis spp. and Schima wallichii (SchimaCastanopsis forest type) is widespread in Central and Western Nepal from 700 to $1500 \mathrm{~m}$ asl. Large part of this forest is situated in areas with dense human population, and a major part of the forest area is replaced by agricultural land and grassland for livestock. The remnants of Schima-Castanopsis forests are often fragmented and degraded from timber harvest, livestock grazing, lopping for fodder, and firewood collection. Undisturbed larger forest areas are more or less absent and no protected areas are designated in this region of Nepal.

The aim of the presented research was to describe the occurrence of ectomycorrhiza fruit bodies under extreme climatic condition and to relate this to patterns found in other parts of Nepal and rest of the world.

\section{Materials and Methods}

The Schima-Castanopsis forests around Pokhara in Central Nepal were explored during several excursions from April 2004 to December 2006. All observations were grouped into three monthly timeframes (from 1st-10th, from 11th to 20th and from 21st to 30th or 31st).

Dates with information:

2004: 22 April; 23 April; 24 April; 26 April; 27 April; 14 Sept.; 15 Sept.; 18 Sept.; 23 Sept.; 24 Sept.; 27 Sept.; 29 Sept.; 1 Oct.; 3 Oct.; 6 Oct.; 13 Oct; 2005: 25 Jan.; 9 April; 12 April; 18 May; 20 May; 22 May; 24 May; 26 May; 27 May; 28 May; 5 June, 11 June; 16 June; 3 July; 4 July; 8 July; 9 July; 17 July; 18 July; 30 July; 31 July; 2 Aug.; 28 Aug.; 29 Aug.; 11Sept.; 26 Sept.; 9 Oct.; 16 Oct.; 30 Oct.; 14 Nov.; 2006: 4 June; 5 June; 8 June; 11 June; 12 June; 14 June; 17 June; 18 June; 22 June; 24 June; 26 June; 29 June; 6 July; 10 July; 14 July; 22 July; 29 July; 30 July; 5 Aug.; 6 Aug.; 11 Aug.; 12 Aug.; 19 Aug.; 28 Aug.; 29 Aug.; 5 Sept.; 9 Sept.; 14 Sept.; 16 Sept.; 24 Sept.; 7 Oct.; 14 Oct.; 21 Oct.; 28 Oct.; 27 Nov.; 9 Dec. 


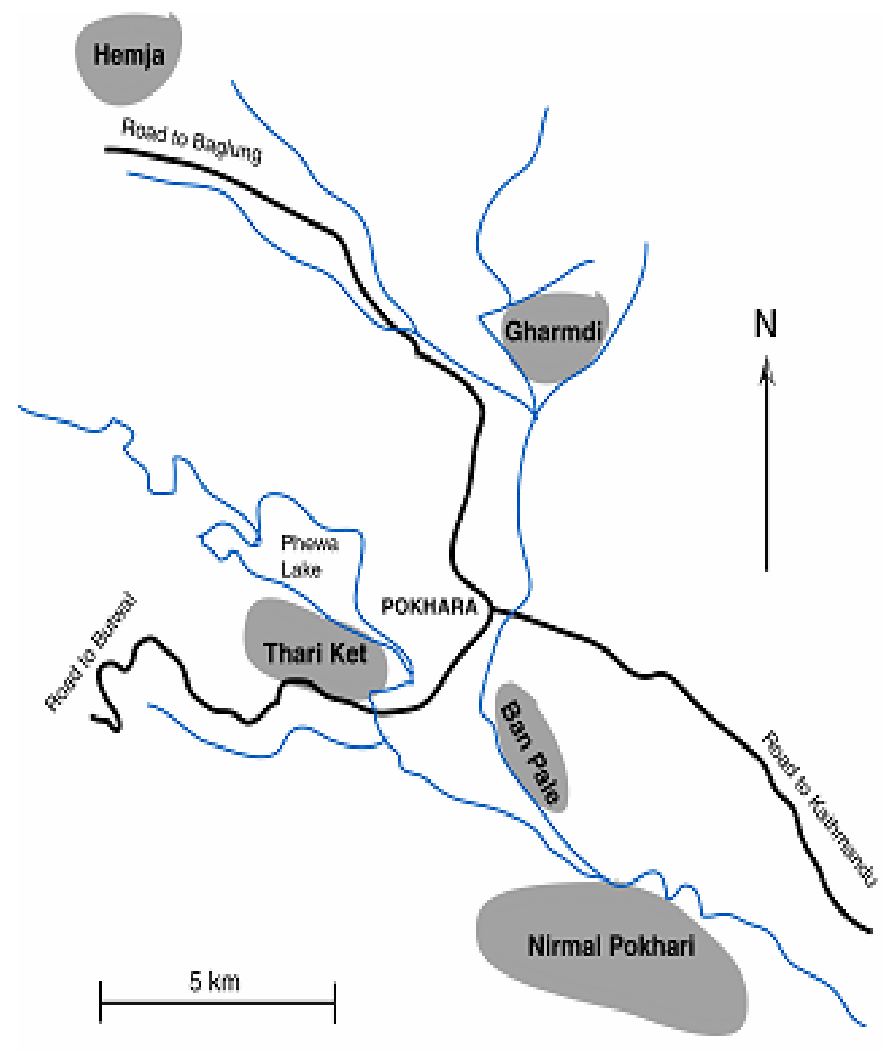

Fig. 1. Map of the study area. Gray shading indicates the forest included in the study.

Sites with information (Fig. 1):

Ban Pale: 15 ha Campus forest of Institute of forestry (52 visits); Hemja (Tibrekot): 109 ha community forest of mixed SchimaCastanopsis (35 visits); Nirmal Pokhari: 100 ha community mixed Castanopsis forest on north facing slopes (3 visits); Gharmdi: dry south exposed mixed Castanopsis forest, partly coppiced (2 visits); Thari Ket: moist Castanopsis dominated forest near lake Phewa (2 visits).

All encountered species found in each field survey were enumerated. Due to the lack of high quality literature covering the region, the identification was done mainly using Japanese, North American, and European literature. Only species identified to species level are included in the present analysis (Table 1).

\section{Results and Discussion}

A total of 58 ectomycorrhizal species were enumerated in the forests nearby Pokhara (Table 1). Mycorrhizal fungi belonging to Russulales (Russula, Lactarius), Boletales (Areoboletus, Austroboletus, Boletus, Boletellus, Gyroporus, Leccinum, Phylloporus, Scleroderma, Strobilomyces, Tylopilus) and Agaricales (Amanita, Laccaria, Tricholoma) were dominating inthe studied forest types. Orders less frequently encountered were Cantharellales (Cantharellus, Craterellus), Hymenochatales (Coltricea) and Theleporales (Thelephora).
The diversity of fungi during the season showed two prominent peaks. First peak was from late May until early July during the premonsoon and early monsoon. Second peak was in late monsoon (late September until mid-October). During the main peak of the monsoon rain in July and August the diversity of fungi was lower (Fig. 2).

Adhikari (2000) described the season for large mushrooms in Kathmandu valley, where the rainfall generally is less than in Pokhara valley, and found that most genera of ecto-mycorrhizal fungi occur from July until October. Exceptions are a few species of Amanita, Boletus and Laccaria, which often show up already in late May. From his data it is not possible to see any bimodular pattern. In a moist warm Temperate Abies firma forest in Japan, Matsuda and Hijii (1998) showed a bimodal pattern in the seasonal changes in numbers of ecto-mycorrhizal species, with one peak from late June to early August and the other larger peak from late September to early October, almost similar to the patterns found in Schima-Castanopsis forest in Nepal. In cold temperate and boreal areas in Europe and North America as well as in the mountainous areas of Nepal, only one peak of the mycorrhizal fungi is found. In a 700 ha area in lower part of Mustang district dominated by conifers, where the climate is Temperate with cold winters and rainfall more evenly distributed around the year, the season for mycorrhizal fungi starts in late June and extends to the first night with frost in October (author's personal observation), peaking in late July and August. Similarly, a Swiss study showed the main fructification of fungi from mid-summer to late autumn (Straatma et al. 2001), but found that some years have a minor peaking in summer beside the major peak in September/October. In a cold boreal coniferous forest in Western Canada Krana-better and Kroeger (2001) found only one peak and the main limiting agent for the fructification of the ectomycorrhizal fungi is likely to be temperature more than moisture. In contrast, studies from Subtropical Mediterranean climate in Southern Europe with winter rain (Richard et al. 2004) show the fructification in the cold season. Interestingly the patterns of monthly temperature in this area are comparable to Pokhara valley. This indicates that moisture is more crucial for the fruit body creation than temperature in subtropical regions.

\section{Conclusions}

Nepal still has a large and diverse mycota to be explored. Understanding the dynamics of ecto-mycorrhizal fungi is important for understanding the ecosystem health and resistance, and an understanding of the diversity is important also for the management of the Nepalese forest. Problems of instability and dieback for plantation forestry in Nepal could well be related to the lack of a proper mycorrhizal mycota and it is important to take this knowledge into account in the forest planning systems. The present survey provided basic information on the phenology of ecto-mycorrhizal fungi in Pokhara valley. However, Nepal houses a magnificent 
diversity of ecosystems and climatic conditions and more studies are still needed to complete the understanding of the dynamic biodiversity.

\section{Acknowledgements}

Thanks to Shiva Devkota, Sanjeeb Bhattarai, Benny Christensen, and Dr. Jacob Heilmann-Clausen for assistance during the fieldwork and to Prof. Abhay K. Das, Yajna P. Timilsina, Achyut R. Gyawali, and Arun Rijal for providing additional information from Hemja. Thanks to Dr. Helle O. Larsen for improving the manuscript.

\section{References}

Adhikari M.K. 2000. Mushrooms of Nepal. P.U. Printers, Kathmandu, Nepal.
Adhikari M.K. and Parajuli P. 1996. Mycorrhizal fungal diversity in the pine forests of Kathmandu valley areas, Nepal: an ecological approach. In: Environment and Biodiversity - In the Context of South Asia (P.K. Jha, G.P.S. Ghimire, S.B. Karmacharya, S.R. Baral, P. Lacoul, eds.), pp. 182197. Ecological Society (ECOS), Kathmandu, Nepal.

Kranabetter J.M. and Kroeger P. 2001. Ectomycorrhizal mushroom response to partial cutting in a western hemlock - western red cedar forest. Canadian Journal of Forest Research 31: 978-987.

Matsuda Y. and Hijii N. 1998. Spatiotemporal distribution of fruitbodies of ectomycorrhizal fungi in an Abies firma forest. Mycorrhiza 8: 131-138.

Richard F., Moreau P.A., Selosse M.A. and Gardes M. 2004. Diversity and fruiting patterns of ectomycorrhizal and saprobic fungi in an old-growth Mediterranean forest dominated by Quercus ilex L. Canadian Journal of Botany 82: 1711-1729.

Straatma G., Ayer F. and Egli S. 2001. Species richness, abundance, and phenology of fungal fruit bodies over 21 years in a Swiss forest plot. Mycological Research 105: 515-523.

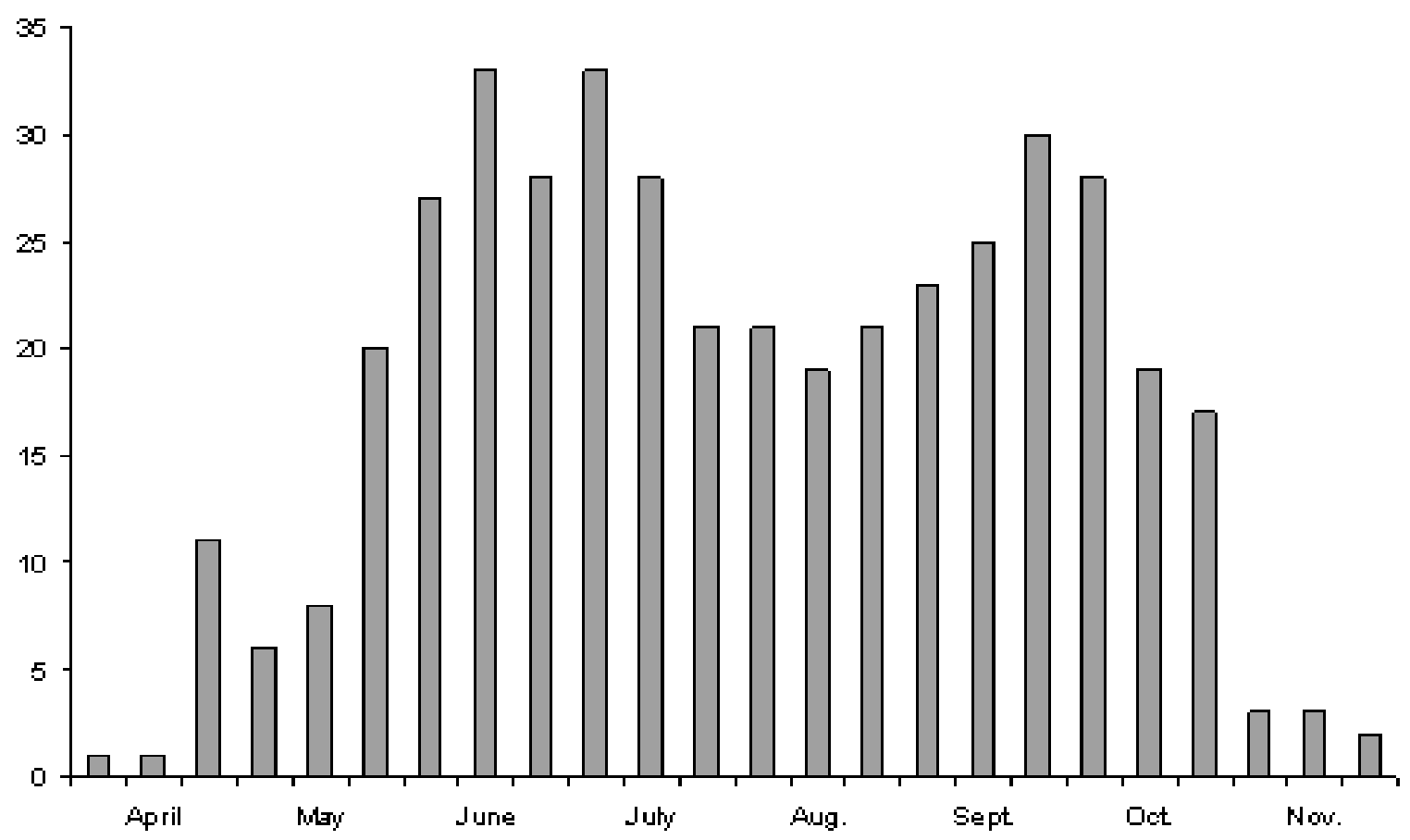

Fig. 2. Number of ecto-mycorrhizal fungi species with fruitbodies in Schima-Castanopsis forest in Pokhara valley. 
Table 1. Observations on 58 different ecto-mycorrhizal fungi species in subtropical Castanopsis forest around Pokhara in Central Nepal. Shaded cells indicate actual observations.

\begin{tabular}{|c|c|c|c|c|c|c|c|c|c|c|c|c|c|c|c|c|c|c|c|c|c|c|c|c|}
\hline \multirow[t]{2}{*}{ Species } & \multicolumn{3}{|c|}{ April } & \multicolumn{3}{|c|}{ May } & \multicolumn{3}{|c|}{ June } & \multicolumn{3}{|c|}{ July } & \multicolumn{3}{|c|}{ August } & & ptemb & & & ctobe & & & vem & \\
\hline & 1 & 2 & 3 & 1 & 2 & 3 & 1 & 2 & 3 & 1 & 2 & 3 & 1 & 2 & 3 & 1 & 2 & 3 & 1 & 2 & 3 & 1 & 2 & 3 \\
\hline Amanita cf. cecilea (Berk. \& Broome) Bas & & & & & & & & 1 & & & & & & & & 1 & & & & & & & & \\
\hline Amanita pantherina (DC.: Fr.) Krombh. & & & & & & 1 & & & & & & & 1 & & & & & & & & & & & \\
\hline Amanita pseudoporphyrea Hongo & & & & & 1 & 1 & & & & & & & & & & & & & & & & & & \\
\hline Amanita punctata (Cleland \& Cheel) D.A. Reid & & & & & & & & & & & & & & & & & & & 1 & 1 & 1 & & & \\
\hline Amanita virosa (Fr.) Bertillon & & & & & & 1 & & & & & & & & & & & & & & & & & & \\
\hline Amanita cf. Iongistriatum (S. Imai) E.J. Gilbert & & & & & & 1 & 1 & & & & 1 & & & & & & & & & & & & & \\
\hline Aureoboletus thibetanus (Pat.) Hongo \& Nagas. & & & & & & 1 & 1 & 1 & 1 & 1 & & & & 1 & 1 & 1 & 1 & 1 & 1 & 1 & 1 & & & \\
\hline Austroboletus subvirens (Hongo) Wolfe & & & & & & 1 & & & & & & & & & & & & & & & & & & \\
\hline Boletellus emodensis (Berk.) Singer & & & & & & 1 & & & & 1 & 1 & & & & & & & & & & & & & \\
\hline Boletellus shichianus (Teng \& Ling) Teng & & & 1 & & & & 1 & 1 & 1 & & & & & & & & & & & & & & & \\
\hline Boletus pseudocalopus Hongo & & & 1 & & 1 & 1 & 1 & 1 & 1 & 1 & 1 & 1 & 1 & 1 & 1 & 1 & 1 & 1 & 1 & 1 & 1 & & & \\
\hline Boletus umbriniporus Hongo & & & & & & & & 1 & 1 & 1 & & & & & & & & & & & & & & \\
\hline Boletus violaceofuscus Chiu & & & & & & 1 & & & & & & & & & & & & & & & & & & \\
\hline Boletus patouillardii Singer & & & & & & 1 & 1 & 1 & 1 & 1 & 1 & & & & & & & & & & & & & \\
\hline Cantharellus cibarius Fr. sensu lato & & & & & & & & & & & & & & & 1 & 1 & 1 & 1 & & & & & & \\
\hline Coltricia cinnamomea (Jacq.) Murrill & & & & & & & & 1 & 1 & 1 & 1 & 1 & 1 & 1 & 1 & 1 & 1 & 1 & 1 & & & & & \\
\hline Craterellus cornucopidoides (L.: Fr.) Pers. & & & & & & & & & & & & & & & & & 1 & 1 & 1 & 1 & 1 & & & \\
\hline Gyroporus cf. longicystidiatus Nagas. \& Hongo & & & 1 & & & & 1 & 1 & & & & & & 1 & 1 & 1 & 1 & 1 & 1 & 1 & & & & \\
\hline Laccaria vinaceoavellanea Hongo & & & & & & & & 1 & 1 & 1 & 1 & 1 & 1 & 1 & 1 & 1 & 1 & 1 & 1 & 1 & 1 & & & \\
\hline Laccaria laccata (Scop. :Fr.) Berk. \& Br. & & & & & & & & & & & 1 & & & & & & & & & & & & & \\
\hline Lactarius aff. quietus (Fr.) Fr. & & & & & & 1 & 1 & 1 & 1 & 1 & 1 & 1 & 1 & 1 & & & & 1 & 1 & & & & & \\
\hline Lactarius camphoratus (Bull. : Fr.) Fr. & & & & & & & 1 & 1 & 1 & 1 & 1 & 1 & & & & & & 1 & & & & & & \\
\hline Russulla alboareolata Hongo & & & 1 & 1 & 1 & 1 & 1 & 1 & 1 & 1 & 1 & 1 & 1 & 1 & 1 & 1 & 1 & 1 & 1 & 1 & 1 & 1 & 1 & 1 \\
\hline Russulla albonigra (Krombh.) Fr. & & & & & & & & 1 & 1 & 1 & 1 & 1 & 1 & 1 & & & & 1 & 1 & & & & & \\
\hline Russulla cyanoxantha (Schäff.) Fr. & & & & & & 1 & 1 & 1 & 1 & 1 & 1 & 1 & 1 & 1 & 1 & 1 & 1 & 1 & 1 & 1 & 1 & & & \\
\hline Russulla favida Fronst & & & & & & 1 & & & & & & & & & & 1 & & & 1 & & & & & \\
\hline Russulla cf. kansaiensis Hongo & & & & & & & & 1 & 1 & 1 & 1 & 1 & 1 & 1 & 1 & 1 & 1 & 1 & 1 & 1 & 1 & & & \\
\hline Russulla nigricans Fr. & & & 1 & & & & 1 & 1 & & & & & & & 1 & 1 & 1 & 1 & 1 & & & & & \\
\hline Russulla cf. sanguinea (Bull.) Fr. & & & & & & & 1 & 1 & 1 & 1 & 1 & 1 & 1 & 1 & 1 & 1 & 1 & 1 & 1 & 1 & 1 & & & \\
\hline Russulla senecis S. Imai & & & & & & 1 & 1 & 1 & 1 & 1 & 1 & 1 & 1 & 1 & 1 & 1 & 1 & 1 & 1 & 1 & 1 & & & \\
\hline Russulla sororia Fr. & & & & & & & & 1 & 1 & 1 & 1 & 1 & 1 & 1 & 1 & 1 & 1 & & & & & & & \\
\hline Russulla virescens (Schäff.) Fr. & & & & & & & 1 & 1 & 1 & 1 & 1 & 1 & 1 & & & & 1 & 1 & 1 & 1 & 1 & & & \\
\hline Scleroderma sinnamariense Mont. & & & & & & 1 & 1 & 1 & 1 & 1 & 1 & 1 & & & & & & & 1 & & & & & \\
\hline Scleroderma verrucosum (Bull.: Fr.) Pers. & & & & & & & 1 & 1 & 1 & 1 & 1 & 1 & 1 & 1 & 1 & 1 & 1 & 1 & 1 & 1 & 1 & 1 & 1 & 1 \\
\hline Strobilomyces confusus Singer & & & & & & & & & & 1 & & & & & & & & & & & & & & \\
\hline Strobilomyces mirandus Corner & & & & & & & 1 & 1 & & & & 1 & 1 & & & & & & & & & & & \\
\hline Strobilomyces seminudus Hongo & & & & & & & 1 & 1 & 1 & 1 & & & & & & & & & & & & & & \\
\hline Thelephora sp. (grey, varted) & & & & & & & & & & 1 & 1 & 1 & 1 & 1 & 1 & 1 & 1 & 1 & 1 & 1 & 1 & & & \\
\hline Thelephora sp. (grey, smooth) & & & & & & & & & & & & & & 1 & 1 & 1 & 1 & 1 & & & & & & \\
\hline Tricholoma bakamatsutake & & & & & & & 1 & & & & & & & & & & & & & & & & & \\
\hline Tylopilus ballounii (Peck) Singer & & & 1 & 1 & 1 & 1 & & & & & & & & & & & & & & & & & & \\
\hline Tylopilus nigirimus (Heim) Hongo \& Endo & & & & & & & & 1 & 1 & 1 & 1 & & & & & & & & & & & & & \\
\hline Tylopilus nigropurpureus (Corner) Hongo & & & & & & & & & & & 1 & & & & & & 1 & 1 & 1 & & & & & \\
\hline Tylopilus fumosipes (Peck) Smith \& Thiers & & & & & & & & & & 1 & & & & & & & & 1 & & & & & & \\
\hline Tylopilus coccineonanus (Corner) Comb. prov. & & & & & & & & & & 1 & & & & & & & & 1 & & & & & & \\
\hline
\end{tabular}

